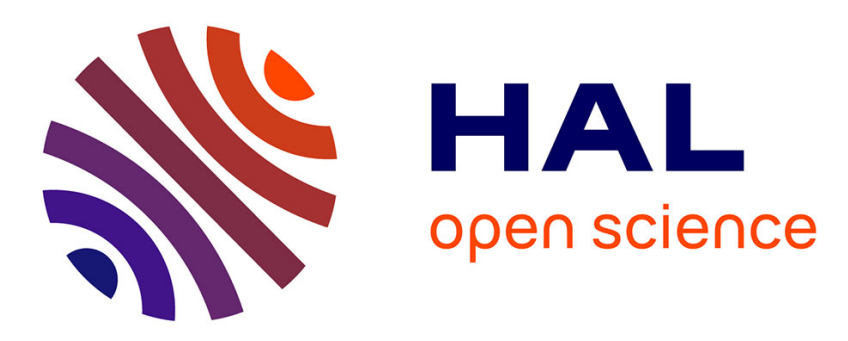

\title{
Influence of Different Microphysical Schemes on the Prediction of Dissolution of Nonreactive Gases by Cloud Droplets and Raindrops
}

\author{
Nathalie Huret, N. Chaumerliac, H. Isaka, E. Nickerson
}

\section{- To cite this version:}

Nathalie Huret, N. Chaumerliac, H. Isaka, E. Nickerson. Influence of Different Microphysical Schemes on the Prediction of Dissolution of Nonreactive Gases by Cloud Droplets and Raindrops. Journal of Applied Meteorology, 1994, 33 (9), pp.1096 - 1109. 10.1175/1520-0450(1994)0332.0.CO;2 . hal01819434

\author{
HAL Id: hal-01819434 \\ https://hal.uca.fr/hal-01819434
}

Submitted on 3 Feb 2021

HAL is a multi-disciplinary open access archive for the deposit and dissemination of scientific research documents, whether they are published or not. The documents may come from teaching and research institutions in France or abroad, or from public or private research centers.
L'archive ouverte pluridisciplinaire HAL, est destinée au dépôt et à la diffusion de documents scientifiques de niveau recherche, publiés ou non, émanant des établissements d'enseignement et de recherche français ou étrangers, des laboratoires publics ou privés. 


\title{
Influence of Different Microphysical Schemes on the Prediction of Dissolution of Nonreactive Gases by Cloud Droplets and Raindrops
}

\author{
N. HuRet, N. ChaUmerliaC, AND H. ISAKa \\ LAMP URA CNRS. Université Blaise Pascal, Aubiere, France \\ E. C. NICKERSON \\ National Oceanic and Atmospheric Administration, FSL, Boulder, Colorado
}

(Manuscript received 14 July 1993, in final form 17 December 1993)

\begin{abstract}
Three microphysical formulations are closely compared to evaluate their impact upon gas scavenging and wet deposition processes. They range from a classical bulk approach to a fully spectral representation, including an intermediate semispectral parameterization. Detailed comparisons among the microphysical rates provided by these three parameterizations are performed with special emphasis on evaporation rate calculations. This comparative study is carried out in the context of a mountain wave simulation. Major differences are essentially found in the contrasted spreading of the microphysical felds on the downwind side of the mountain. A detailed chemical module including the dissolution of the species and their transfer between phases (air, cloud, and rain) is coupled with the three microphysical parameterizations in the framework of the dynamical mesoscale model. An assessment of the accuracy of each scheme is then proposed by comparing their ability to represent the drop size dependency of chemical wet processes. The impact of evaporation (partial versus total) upon the partition of species between gas and aqueous phases is also studied in detail.
\end{abstract}

\section{Introduction}

The process of wet deposition is one of the main mechanisms for removing trace gases and aerosol particles from the atmosphere (Iribarne and Cho 1989). Modeling of cloud chemistry and wet deposition is a very complex task because dynamical and microphysical processes are linked together and strongly interact with chemical processes. Dynamical processes are responsible for the transport of water, gas, and aerosol particles, but the chemical aqueous-phase concentrations are determined by the microphysical history of the droplets, including condensation and coalescence processes. Although the interactions between cloud processes and chemical processes have received considerable attention (e.g., Flossmann et al. 1987; Ayers and Larson 1990; Carmichael and Peters 1984), much less is known about aqueous phase chemistry than about the processes that are responsible for the formation, growth, and decay of a cloud.

Ogren and Charlson (1992) have shown that there are large variations in the temporal and spatial scales of cloud chemistry reactions, and this provides a partial explanation for the coarse approximations made in

Corresponding author address: Dr. N. Huret, Laboratoire de Meteorologie Physique, Universite Blaise Pascal-C.N.R.S., 24, avenue des Landais, 63177 Aubiere Cedex, France. modeling studies of such processes. Modeling studies such as those of Hales (1989) and Ferretti et al. (1993) use a bulk microphysical parameterization like the one from Kessler (1969) that treats droplet spectra as a single well-mixed ideal solution of droplets that maintains vapor-liquid equilibrium with surrounding trace gases. Experimental results of Noone et al. (1988) and theoretical results obtained by Flossmann et al. (1987), however, show a dependency between drop size and the chemical concentration inside the drops. In addition, Hegg and Larson (1990) and Chaumerliac et al. (1990) have shown the importance of microphysical parameterizations on gas scavenging and chemical reactions in aqueous phase and in wet deposition. Other studies (Lee 1986; Roelofs 1992) have used a cloud model that describes in detail the evolution of aerosol and droplet spectra but that does not take into account the dynamical processes that transport gas species and interact strongly with microphysical processes.

In this paper, we examine the impact of three different microphysical parameterizations on gas scavenging and wet deposition in a mesoscale model. The parameterizations range from the very simple to the very complex and include the bulk approach developed by Kessler (1969), a semispectral approach developed by Berry and Reinhardt (1974ab), and a complete spectral approach developed by Le Cam and Isaka (1989). Since we are focusing on gas scavenging and 
wet deposition, the condensation stage on aerosol particles has been neglected as a first step in all three parameterizations.

The mesoscale framework of this study enables us to take into account interactions between microphysical and dynamical processes. We will examine the capability of the three parameterizations to partition gases between air, cloud water, and rainwater and, for the spectral scheme, the distribution of chemical species inside the raindrops. Two different gaseous species, one very soluble and one less soluble, are transported, absorbed, and desorbed in both cloud droplets and raindrops. In section 2, the microphysical models are described. Gas scavenging by the three microphysical schemes is then discussed in the framework of a twodimensional mountain wave scenario that couples dynamics, microphysics, and aqueous-phase chemistry.

\section{The microphysical model}

\section{a. Description}

The Kessler ( 1969 ) scheme (hereafter K), the Berry and Reinhardt (1974a,b) scheme (hereafter BR), and the spectral scheme (hereafter SP) are summarized in this section. A description of the mesoscale model used in this study is given by Nickerson et al. (1986), and a comparative study of the Kessler (1969) and Berry and Reinhardt $(1974 a, b)$ formulations can be found in Richard and Chaumerliac (1989). The spectral scheme that we have used explicitly resolves the stochastic coalescence equation and is based on the work of Le Cam and Isaka (1989).

Condensation is treated in the same way for all three parameterizations. Cloud-water mixing ratio is diagnosed from the prognostic variable $q$, which is the sum of the water vapor mixing ratio $q_{v}$ and the cloud-water mixing ratio $q_{\mathrm{cw}}$. When supersaturation occurs, $q_{v}$ is equal to the saturation vapor mixing ratio $q_{v s}$ and the excess of vapor is condensed into cloud water. For both the BR and the SP parameterizations, microphysical processes depend on the type of air mass considered and the clouds are represented by a lognormal spectrum having a mean diameter $D_{\mathrm{cw}}$ and a standard deviation $\sigma_{c}$.

The treatment of rainwater in the three parameterizations differs along with the shape of the droplet spectra, the formulation of the terminal velocity, the number of prognostic variables, and the representation of the microphysical processes. In the $\mathrm{K}$ scheme, rainwater is represented by a Marshall-Palmer (1948) distribution, and in the BR scheme it is represented by a lognormal distribution. In the SP scheme, however, no hypothesis is made regarding the shape of the raindrop distribution. A single parameter, the total number of raindrops, defines the Marshall-Palmer distribution, while two parameters, the total number of raindrops and the mean diameter, define the lognormal distribution. The Marshall-Palmer (1948) raindrop mass density distribution is centered on large diameters, whereas the mass density function for the lognormal distribution varies during the course of the simulation and can be centered on small diameters or large diameters. The SP scheme makes no assumption regarding the shape of the raindrop spectra and hence allows for the greatest flexibility in representing such spectra.

In the BR and SP schemes, the terminal velocity is calculated using the formulation of Berry and Pranger (1974), which is a function of the Reynolds number and results in terminal velocities that are smaller than those given by the Kessler (1969) formulation for small drops. This behavior has important implications for the accretion and sedimentation rates, which are strongly dependent on the raindrop terminal velocity.

The prognostic variables for rainwater mixing ratio and the microphysical processes considered in the three parameterizations are now summarized. The $\mathrm{K}$ parameterization is derived from empirical considerations and observations and hence is the more parameterized scheme. It considers only the evolution of the rainwater mixing ratio $q_{\mathrm{rw}}$ through autoconversion and accretion and assumes that raindrops are distributed according to a Marshall-Palmer (1948) spectrum. The BR scheme is a semispectral scheme because it was derived from results obtained by integrating a fully spectral microphysical model, including autoconversion, accretion, and self-collection processes. The cloud droplets and raindrop spectra both are represented by lognormal distributions. In this case, the predictive variables for rainwater are the rainwater mixing ratio $q_{\mathrm{rw}}$ and the total number of drops $N_{\mathrm{rw}}$, which allow for the evolution of the mean raindrop diameter. The lognormal scheme therefore provides an additional degree of freedom not available in the $\mathrm{K}$ scheme. In the SP scheme, cloud droplets and raindrops are represented by 50 classes of radius between $1 \mu \mathrm{m}$ and $5 \mathrm{~mm}$. Different tests on the efficiency of the collection kernel allow us to classify the drops as rainwater if their diameter is greater than $60 \mu \mathrm{m}$ and as cloud droplets otherwise. The predictive variables that describe the evolution of rainwater by coalescence are the number concentration of raindrops distributed in 30 classes of radius between $60 \mu \mathrm{m}$ and $5 \mathrm{~mm}$. The shape of the raindrop spectrum is not assumed, and the scheme provides 30 degrees of freedom.

The autoconversion rate in the BR scheme is dependent on the type of air mass and on the cloud-water mixing ratio. In the $\mathrm{K}$ scheme, autoconversion is a linear function of the cloud-water mixing ratio, and rainwater cannot appear if the cloud-water mixing ratio is smaller than some specified value that is usually taken to be $0.5 \mathrm{~g} \mathrm{~m}^{-3}$. In both the SP and the BR schemes, cloud water can be converted into rainwater for small cloud-water mixing ratios.

In addition to accretion processes that are considered by the K scheme, the BR and the SP schemes allow us to consider different types of raindrop distributions 
whose mean diameter may be centered on large drops or on small drops. When the raindrop spectrum is centered on small drops, the accretion rate is greater than it would be using the $\mathrm{K}$ formulation; when the raindrops are centered on large drops, the accretion rate is smaller than it would be from the $\mathrm{K}$ formulation. In the $\mathrm{BR}$ and the SP representations, sedimentation rates strongly depend on the mean diameter of the raindrop spectrum, and hence when the mean droplet diameter is small, the sedimentation rate is smaller than that for the $\mathrm{K}$ scheme. The increased flexibility of the BR formulation with respect to the $\mathrm{K}$ scheme is even more pronounced for the SP scheme because of the absence of a prescribed shape for the droplet spectra.

Because the below-cloud evaporation is an important process for the release of gas, we focus our attention on the formulation of evaporation rates used in the three parameterizations. The rate of change of the rainwater mixing ratio due to evaporation of raindrops using the $\mathrm{K}$ scheme is deduced from experimental data obtained by Gunn and Kinzer (1949) integrated over the Marshall-Palmer spectrum and is given as follows:

$$
\left(\frac{d q_{\mathrm{rw}}}{d t}\right)_{\mathrm{K}}=0.17 \times 10^{-3} N_{0}^{0.35}\left(\rho_{a} q_{\mathrm{rw}}\right)^{0.5}\left(q_{v s}-q_{v}\right),
$$

where $N_{0}$ represents the total number of drops and is set equal to $10^{7} \mathrm{~m}^{-4}$ according to observational data given by Waldvogel (1974). In this case, the evaporation rate depends only on the rainwater mixing ratio.

In the BR scheme, the evaporation rate is based on the theoretical formulation given by Pruppacher and Klett (1978) integrated over a lognormal spectrum and includes ventilation effects together with a pressure and temperature dependency;

$$
\begin{aligned}
\left(\frac{d q_{\mathrm{rw}}}{d t}\right)_{\mathrm{BR}}= & \frac{2 \pi}{A_{3}} N_{\mathrm{rw}}\left[-4.33 \times 10^{-5} D_{\mathrm{rw}}^{3}+5.31 D_{\mathrm{rw}}^{2}\right. \\
& \left.\times \exp \left(-\sigma_{r}^{2}\right)+0.572 D_{\mathrm{rw}} \exp \left(\sigma_{r}^{2}\right)\right] \\
& \times \frac{q_{v s}-q_{v}}{q_{v s}} .
\end{aligned}
$$

The ventilation effects are included through a ventilation factor $f$, which can be expressed as a function of the Reynolds number Re and the Schmidt number Sc, following Beard and Pruppacher (1971):

$$
f=0.78+0.308 \mathrm{Re}^{1 / 2} \mathrm{Sc}^{1 / 3} \text {. }
$$

The expression $\mathrm{Re}^{1 / 2} \mathrm{Sc}^{1 / 3}$ is then fitted as a function of diameter $D_{\mathrm{rw}}$ by

$$
\begin{aligned}
\mathrm{Re}^{1 / 2} \mathrm{Sc}^{1 / 3}=-1.406 \times 10^{6} D_{\mathrm{rw}}^{2} & +1.725 \\
& \times 10^{4} D_{\mathrm{rw}}-0.675
\end{aligned}
$$

An additional term is included to take into account the number of raindrops that completely evaporate during the time step $d t$. A critical diameter value is calculated that corresponds to the raindrop size below which they completely evaporate. This diameter is obtained by

$$
\int_{0}^{D_{\text {crit }}} D d D=\int_{t}^{t+d t} \frac{4}{A_{3} \rho_{w}}\left(1-\frac{q_{v}}{q_{s}}\right)
$$

and

$$
A_{3}=\frac{R T}{e_{s} D_{v}}+\frac{L_{v}}{k_{a} T}\left(\frac{L_{v}}{R_{v} T}-1\right)
$$

where $T$ is the temperature, $L_{v}$ the vapor latent heat, $D_{v}$ the water vapor diffusivity, $k_{a}$ the thermal conductivity, $R_{v}$ the universal gas constant, and $e_{s}$ the saturation vapor pressure.

Then the number of drops evaporating during a time step is calculated:

$$
N_{\text {eva }}=\int_{0}^{D_{\text {crit }}} \frac{N_{\mathrm{rw}}}{(2 \pi)^{1 / 2} \sigma_{r} D} \exp \left[-\frac{1}{2 \sigma_{r}^{2}} \ln ^{2}\left(\frac{D}{D_{0}}\right)\right] d D .
$$

This formulation describes in more detail the evolution of the rainwater mixing ratio by the evaporation process in terms of its dependency on temperature and mean raindrop diameter. The evolution of the total number of raindrops allows us to take into account partial evaporation.

In the SP parameterization, the evolution of a raindrop of diameter $D$ by evaporation is calculated explicitly using the theoretical formulation from Pruppacher and Klett (1978):

$$
\left(\frac{d D}{d t}\right)_{\mathrm{eva}}=\frac{4 f}{A_{3} D \rho_{w}}\left(1-\frac{q_{v}}{q_{v s}}\right)
$$

The corresponding variation of the concentration $n(D)$ of drops of diameter $D$ is then given by

$$
\left[\frac{d n(D)}{d t}\right]_{\mathrm{eva}}=-\frac{\partial}{\partial r}\left[n(D)\left(\frac{d D}{d t}\right)_{\mathrm{eva}}\right] .
$$

In this formulation, all drops react to the evaporation process in their own way as a function of their diameter. Temperature, pressure, and ventilation effects are also taken into account. The evolution of the rainwater mixing ratio is strongly correlated with the number of raindrops in each diameter class. The shape of the spectrum before and after evaporation processes is not limited to an exponential or lognormal form as it is in the $\mathrm{K}$ or BR schemes. Total evaporation and partial evaporation are described in detail, whereas partial evaporation is not taken into account at all in the $\mathrm{K}$ scheme and only partially taken into account in the BR scheme. As we will see later, the process of partial evaporation is a very important process that serves to concentrate chemical species in raindrops.

To estimate the efficiency of each scheme to describe the evaporation process, we have made a series of tests. 
Evaporation rates for the three schemes are presented in Fig. 1 for a pressure of $1000 \mathrm{mb}$. In contrast to K, the BR and SP schemes are sensitive to the number of drops and also to the mean diameter of the raindrop spectrum. When raindrop spectra are centered on small diameters $\left(N_{\mathrm{rw}}=100 \mathrm{~L}^{-1}\right)$ the evaporation rate is greater than that calculated for large drops $\left(N_{\mathrm{rw}}=1\right.$ $\mathrm{L}^{-1}$ ). In the two cases presented, the evaporation rates calculated by BR are greater than those calculated by $\mathrm{SP}$, and this overestimate in absolute magnitude by the BR scheme is especially important for small drops. In addition, the SP scheme allows us to calculate evaporation rates when rainwater is represented by a bimodal distribution centered on both small and large drop diameters. The curve representing the evaporation rate calculated with the SP scheme assuming that half the rainwater mixing ratio is distributed on small drops and half on large drops shows that the presence of small drops substantially increases the evaporation rate in comparison with results obtained for the case of a single distribution on large drops. On the other hand, the presence of large drops slightly decreases the evaporation rate compared to results obtained with a single distribution centered on small drops.

The BR scheme gives a more realistic description of the evaporation process than does the $\mathrm{K}$ scheme, as shown by Richard and Chaumerliac (1989) when they compared the two schemes for the simulation of orographic precipitation. The SP scheme reacts in the same way as the BR scheme when a single lognormal distribution is assumed. When one considers the case where rainwater is distributed over a double lognormal spectrum, however, the behavior of the SP scheme is very different and more sensitive to the evaporation process than the BR scheme.

The flexibility of the SP scheme due to its detailed representation of rainwater appears to be very important, because in the dynamical framework the shape of the spectrum is not defined a priori, and large numbers of small and large drops can coexist in the same area. With the SP scheme, the large number of predictive variables brings additional degrees of freedom that provide more detailed information about raindrop size spectrum and facilitate the representation of the physical processes that control the evolution of the raindrop spectrum. The SP scheme gives much more flexibility in the representation of all microphysical processes, and with this flexibility comes the potential for a more realistic simulation.

\section{b. Results from the mountain wave scenario}

A complete description of the mountain wave scenario can be found in Richard and Chaumerliac (1989) and Chaumerliac et al. (1990). It consists of a twolayer atmosphere over an idealized bell-shaped mountain. The horizontal homogeneous initial wind speed is $20 \mathrm{~m} \mathrm{~s}^{-1}$, and a relative humidity of $80 \%$ is assumed

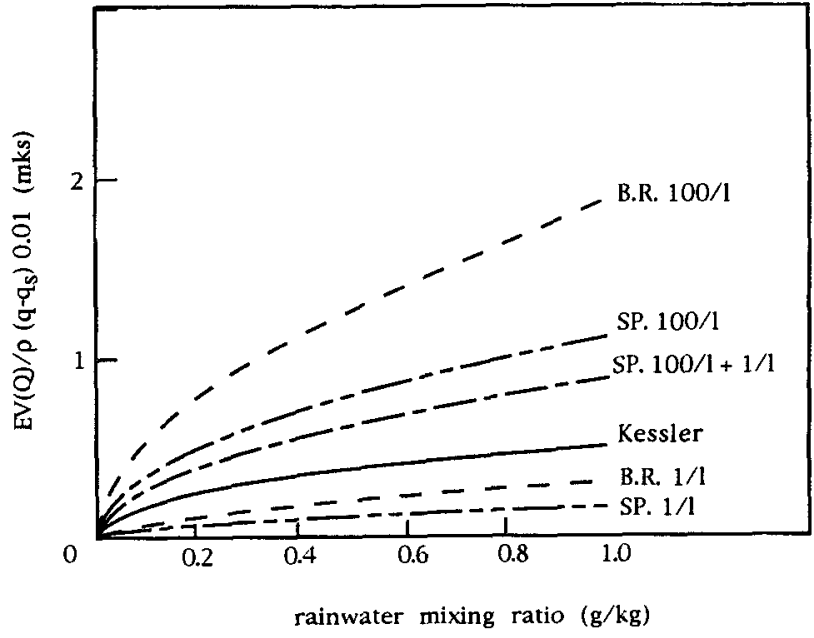

FIG. 1. Evolution of the evaporation rate as a function of rainwater mixing ratio for the Kessler $\mathrm{K}$, Berry and Reinhardt $\mathrm{BR}$, and spectral SP schemes at $1000 \mathrm{mb}$. For the two last formulations, tests have been performed considering the total number of drops $N_{\mathrm{rw}}$ equal to $100 \mathrm{~L}^{-1}$ and to $1 \mathrm{~L}^{-1}$.

below $3 \mathrm{~km}$. Simulations are performed using a twodimensional version of the mesoscale model of Nickerson et al. (1986) over a horizontal domain of 300 $\mathrm{km}$ and a horizontal grid length of $10 \mathrm{~km}$. The time step is $10 \mathrm{~s}$ and the simulation duration is $6 \mathrm{~h}$. Figures $2 \mathrm{a}, 2 \mathrm{~b}$, and $2 \mathrm{c}$, present the vertical cross sections of cloud-water mixing ratio, rainwater mixing ratio, and precipitation rates for the three parameterizations, and the maximum values are given on the upper-right corner of each figure.

As described in the previous section, BR and SP autoconversion processes depend on the cloud-water airmass type. As Beard and Ochs (1993) mentioned, this feature appears significant considering warm rain initiation. The $\mathrm{K}$ scheme does not contain this feature. We have selected cloud-water parameters corresponding to a maritime air mass, where the mean diameter $D_{\mathrm{cw}}=27.5 \mu \mathrm{m}$ and the standard deviation $\sigma_{c}=0.2775$. For the SP scheme, we also adopt this hypothesis for the cloud droplet spectrum that then evolves through downstream distributions up to raindrops. As we can see in Fig. 2a, with this assumption we have the same order of magnitude for the cloud-water mixing ratio, approximately $0.55 \mathrm{~g} \mathrm{~kg}^{-1}$, for the three parameterizations. This condition allows us to be in similar conditions with respect to the conversion of cloud water to rainwater and will facilitate the comparison of the three parameterizations.

Maximum values for cloud-water mixing ratio are the same order of magnitude for all three schemes, but in the $\mathrm{K}$ scheme cloud water exists on the downwind side of the mountaintop. This result is due to the formulation of the autoconversion process in $\mathrm{K}$ that is not allowed to create rainwater if the cloud-water mixing ratio is smaller than $0.5 \mathrm{~g} \mathrm{~m}^{-3}$. In the BR and SP 
KESSLER
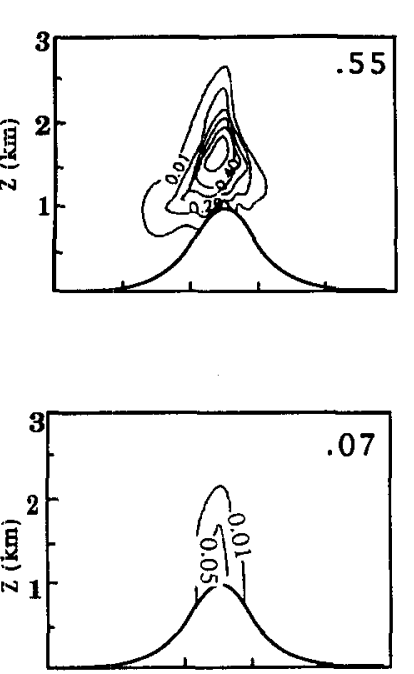

07

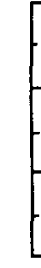
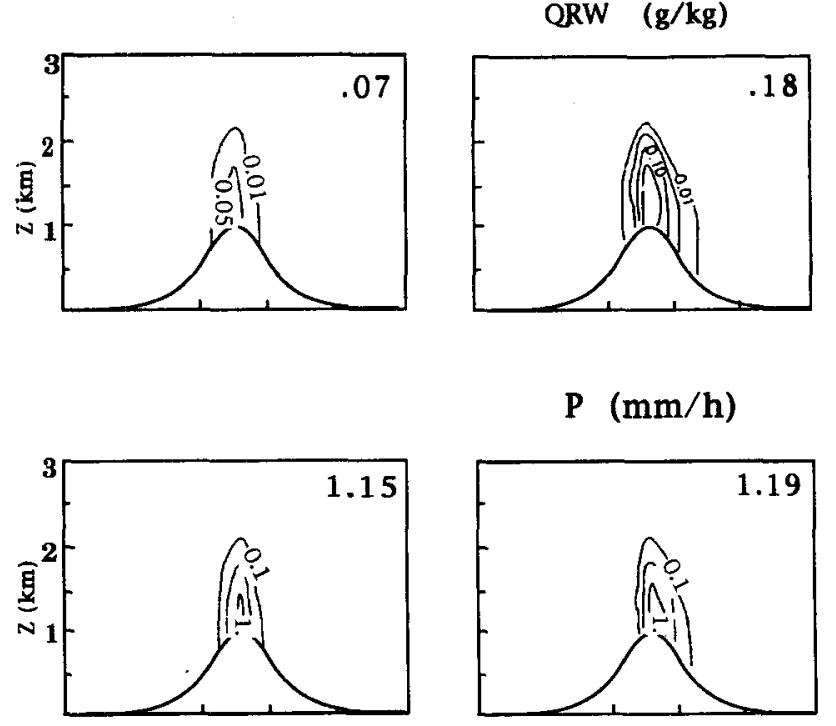

\section{SPECTRAL}

P $(\mathrm{mm} / \mathrm{h})$
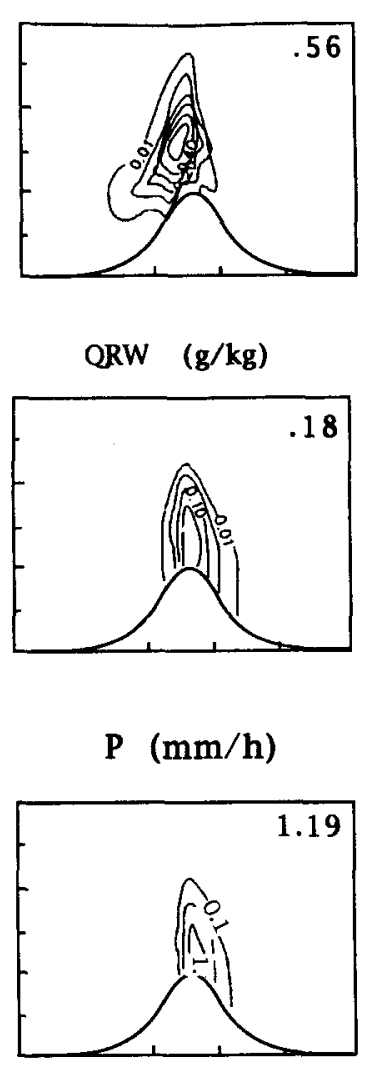

QRW $(\mathbf{g} / \mathbf{k g})$
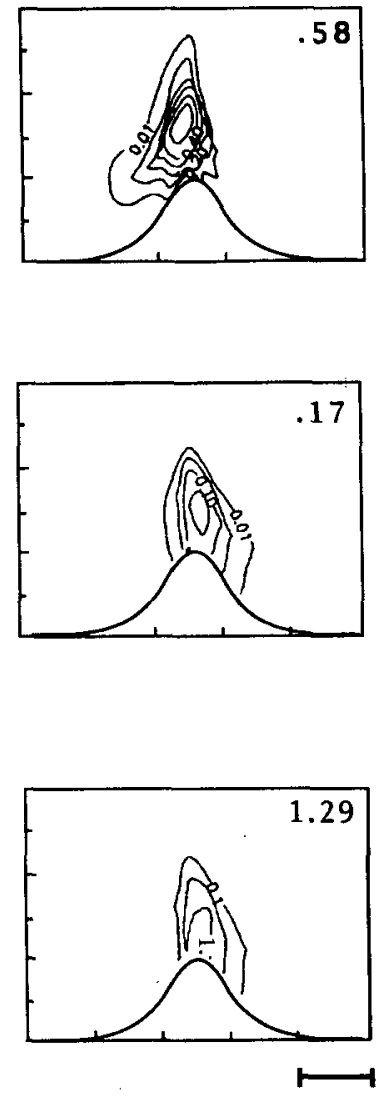

$50 \mathrm{~km}$

FIG. 2. Vertical cross section obtained after' $6 \mathrm{~h}$ of simulation time of cloud-water mixing ratio, rainwater mixing ratio, and precipitation rate for the $\mathrm{K}, \mathrm{BR}$, and SP parameterizations. Maximum values are given in the upper-right corner of each figure.

schemes, the cloud water extends from the upwind side to the top of the mountain but not downwind because the autoconversion process is efficient for small cloudwater mixing ratios.

Precipitation rates in Fig. 2c are also of the same order of magnitude, $1.20 \mathrm{~mm} \mathrm{~h}^{-1}$, but differ in their spatial extent. The maximum precipitation rate for the $\mathrm{K}$ scheme is centered at the top of the mountain, while in the BR and SP schemes the maximum precipitation rates are located on the downwind side of the mountain. This behavior is especially noticeable in the SP scheme. In contrast to the cloud-water mixing ratio and precipitation rates, Fig. $2 \mathrm{~b}$ shows that the rainwater mixing ratios with the BR and SP schemes are markedly greater than with the $\mathrm{K}$ scheme, and like precipitation rates, the spatial extent also extends to the downwind side of the mountain.

These differing behaviors can be explained by considering the mass density functions of rainwater given in Fig. 3 for three grid points on the upwind side, downwind side, and on the top of the mountain, respectively, for three vertical levels. The $\mathrm{K}$ mass density functions are systematically centered on larger diameters than either BR or SP ones. The large drops in the $\mathrm{K}$ scheme have greater terminal velocities, and precipitation occurs rapidly. When rainwater is created, the raindrops have sufficient size to precipitate immediately. Raindrops do not remain aloft; consequently, the precipitation rate is large for the rainwater mixing ratios that develop, and the maximum value is located on the top of the mountain. Smaller drops in the BR and SP mass density function are more easily transported by wind drift to the downwind side of the mountain.

For the BR and SP schemes, we can examine the different processes occurring during the formation of precipitation as a function of the distance from the top of the mountain. We can consider that on the upwind 


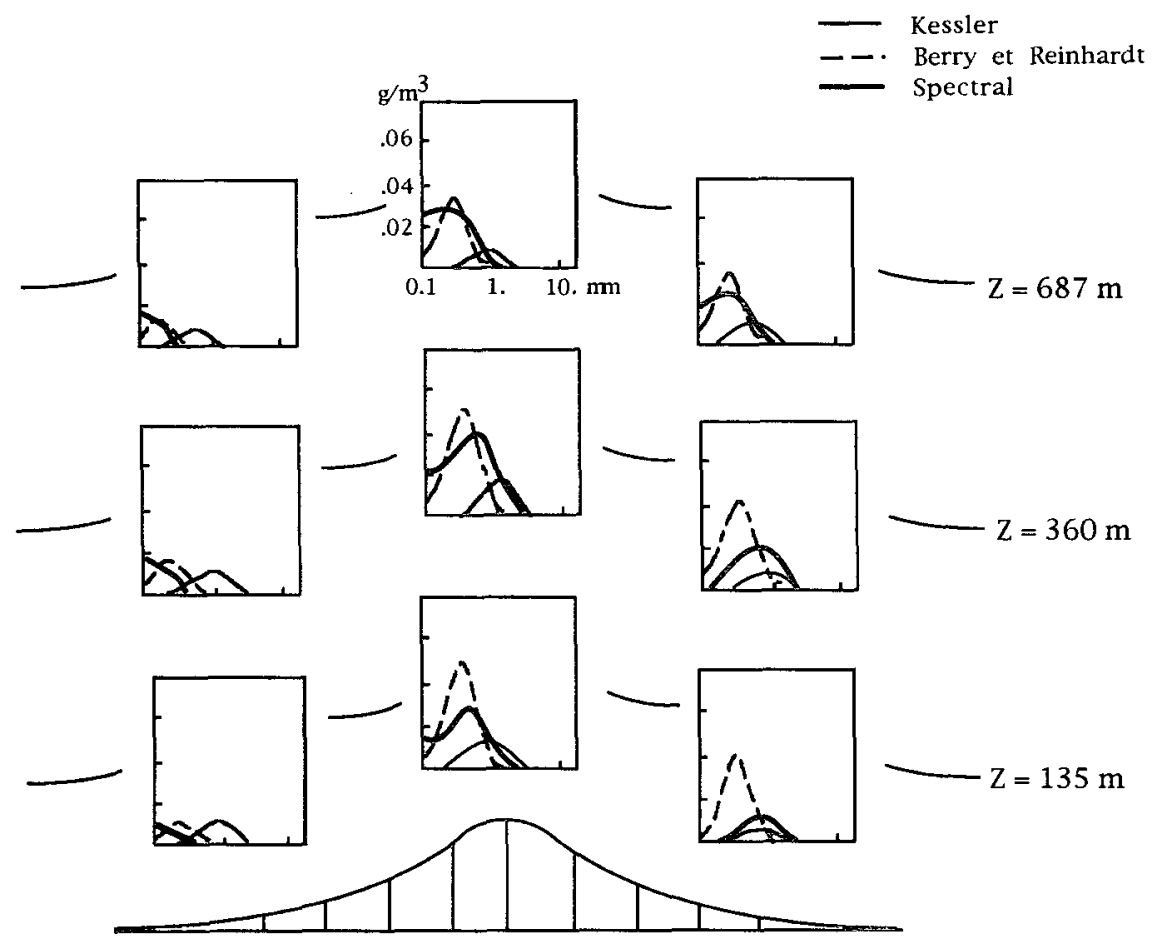

FIG. 3. Mass density functions for raindrops obtained with $\mathrm{K}$ (thin line), BR (dashed line), and SP (full line) schemes, for three grid points located at the top of the mountain, upwind, and downwind from the mountaintop, respectively, for three vertical levels in the model. These vertical levels are indicated on the right-hand side of the figure.

side, autoconversion processes occur; on the top of the mountain, accretion processes govern the evolution of rainwater; and on the downwind side, sedimentation and evaporation processes dominate. On the downwind side of the mountain, small drops with an average diameter of $0.2 \mathrm{~mm}$ are created in both schemes by the autoconversion of cloud water. On the top of the mountain, accretion processes lead to the formation of larger drops with a mean diameter equal to $0.4 \mathrm{~mm}$ with the BR scheme and varying from 0.1 to $0.9 \mathrm{~mm}$ with the SP scheme. In this region, small drops are present in the SP scheme, and the raindrop spectrum covers a larger range of drop sizes than in the BR spectrum. In the BR scheme, the standard deviation remains fixed during the simulation, and consequently large numbers of small drops and large drops cannot exist simultaneously in the same location. As previously mentioned in section 1 , the presence of small drops increases the accretion rate, and the spreading of the raindrop spectrum is more efficient in initiating the self-collection process that leads to the creation of large drops. Consequently, on the downwind side the raindrop spectrum in the SP scheme is centered on larger diameters than that of the BR scheme. In the SP scheme at this location at $687 \mathrm{~m}$ in altitude, small drops are always present. The effect of evaporation processes can be clearly seen because at $360 \mathrm{~m}$ in altitude the small drops have disappeared. Evaporation processes remove the small drops from the spectrum. This behavior is less noticeable in the BR scheme because the spreading of the spectrum is fixed and the evaporation process reduces only the mean diameter of the distribution. The differences between BR and SP are due also to the treatment of partial evaporation, which in the case of the SP scheme does not shift the spectrum to the smaller drop sizes as BR does; further, the presence of larger drops in SP allows for a continuous increase in the diameter of raindrops by self-collection.

To extract more information concerning the details of the microphysical processes, we have plotted in Fig. 4 the vertical profiles of the variations of rainwater mixing ratio by autoconversion, accretion, evaporation, and sedimentation on the downwind side of the mountain for the three parameterizations. Autoconversion and accretion processes are of the same order of magnitude in the BR and SP schemes. The sedimentation rate is lower for the $\mathrm{K}$ scheme than for BR and SP schemes because raindrops have previously fallen out on the top of the mountain. The SP sedimentation rate is greater than the BR rate because the raindrop spectrum is centered on larger diameters in the SP scheme. Major differences appear when considering the evaporation process. In contrast to the results obtained in section 1, the evaporation rate is greater in the SP scheme than in the BR scheme. This result comes from the large spreading of the raindrop spec- 


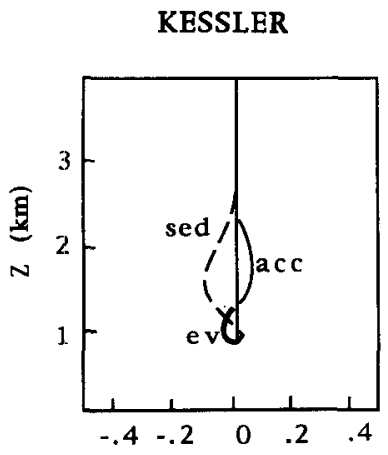

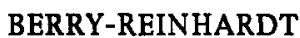

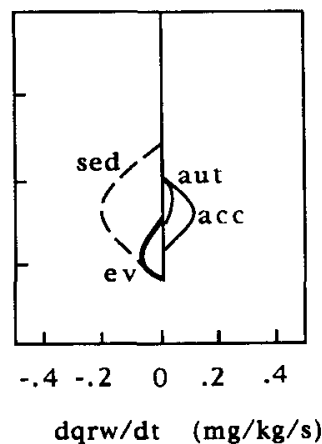

SPECTRAL

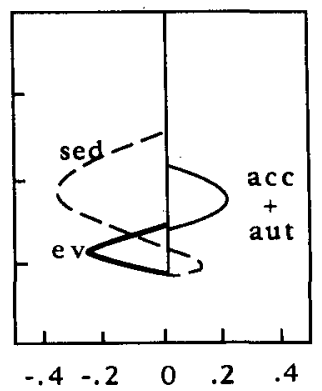

FIG. 4. Vertical profiles of the variation of rainwater mixing ratio $d q_{\mathrm{rw}} / d t\left(\mathrm{mg} \mathrm{kg}^{-1} \mathrm{~s}^{-1}\right)$ due to autoconversion, accretion, sedimentation, and evaporation processes on the downwind side of the mountain for the three parameterizations.

trum in the SP scheme. More small drops are present in this part of the domain and evaporate; also, large drops can partially evaporate. The evaporation rate is strongly dependent on the shape of the raindrop spectrum.

The rainwater mixing ratios obtained by the $B R$ and SP schemes are quite similar in intensity and spatial distributions and both contrast with results from the $\mathrm{K}$ scheme. In the BR and SP parameterizations, the rainwater is represented by smaller drops that are more sensitive to wind drift. The maximum of rainwater mixing ratio is greater than that of the $\mathrm{K}$ scheme and is centered on the downwind side of the mountain. This feature is emphasized in the SP scheme. With respect to spectral distributions, the spectral scheme appears to provide a better representation of the microphysical processes because the shape of the spectrum is not defined a priori. Larger drops are created because small drops are present, and the accretion process is more efficient in initiating self-collection. These differences between evaporation, sedimentation, and raindrop spectra will affect the scavenging processes and wet deposition.

\section{Chemical model}

In this section, we describe in detail the chemical model used with the three microphysical parameterizations. We consider a soluble nonreactive gas. In the $\mathrm{K}$ and $\mathrm{BR}$ schemes, three predictive variables are considered that represent the concentration in gaseous phase $C_{g}$, aqueous phase in cloud water $C_{c}$, and aqueous phase in rainwater $C_{r}$. In the SP scheme, dissolved gas in rainwater is represented by 30 variables corresponding to the concentration of gas in aqueous phase as a function of raindrop diameter $C_{r}(D)$. The time of change of each concentration for a given species is calculated as follows:

$$
\begin{aligned}
& \frac{d C_{g}}{d t}=-S_{\mathrm{dis}}-S_{\mathrm{sca}}+S_{\mathrm{eva}} \\
& \frac{d C_{c}}{d t}=S_{\mathrm{dis}}-S_{\mathrm{acc}}-S_{\mathrm{aut}} \\
& \frac{d C_{r}}{d t}=S_{\mathrm{sca}}+S_{\mathrm{aut}}+S_{\mathrm{acc}}+S_{\mathrm{sed}}-S_{\mathrm{eva}} .
\end{aligned}
$$

Here $S$ represents the various sources and sinks of the concentrations. The subscript aut refers to autoconversion of cloud droplets into raindrops; acc to accretion of cloud droplets by raindrops; in the case of the SP scheme, scol represents the change in raindrop concentration by self-collection in each size category of diameter $D$; and eva represents the change in raindrop concentration due to evaporation. If raindrops evaporate completely, all the chemical species move to the gas phase, and if evaporation is partial, the concentration within the raindrops increases. The subscripts dis and sca designate, respectively, the absorption or desorption of gas in aqueous phase for cloud droplets and raindrops. The left-hand sides of Eqs. (10)-(13) include transport and diffusion terms.

As already mentioned, in spite of the hypothesis made for the cloud droplet spectrum in case of the SP scheme, we compute the absorption/desorption of gases over the whole range of drop diameters and redistribute the aqueous phase concentrations between cloud droplets and raindrops adopting a cut diameter of $60 \mu \mathrm{m}$. This leads to a last equation for the SP scheme written as

$$
\begin{aligned}
\frac{d C_{r}(D)}{d t}= & S_{\mathrm{sca}}(D)+S_{\mathrm{aut}}(D)+S_{\mathrm{acc}}(D) \\
& +S_{\mathrm{scol}}(D)+S_{\mathrm{sed}}(D)-S_{\mathrm{eva}}(D)
\end{aligned}
$$

where $S_{\mathrm{sca}}=\sum_{i=1}^{N} S_{\mathrm{sca}}(D)$, and where $N$ is the number of classes representing the raindrop spectrum. 
We now focus our attention on the assumptions that were used to absorb and desorb the gases in the liquid phase. The dependency of aqueous phase chemistry on drop size has been demonstrated both experimentally (Noone et al. 1988) and theoretically (Flossmann et al. 1987). The scavenging of gases by water drops is a very complex process involving diffusion of gases toward gas-water interface, transfer through the interface into the drop, diffusion and liquid circulation within the drop, and chemical reactions in the liquid phase. With the method employed in the SP scheme, the variation in aqueous phase takes into account the diameter of both cloud droplets and raindrops. Mass transfer limitations are considered for cloud droplets and raindrops. According to Schwartz (1986), processes involving scavenging of gas are parameterized using a mass transfer coefficient $k_{t}$ given by

$$
k_{t}=\left(\frac{a^{2}}{3 D_{g}}+\frac{4 a}{3 \bar{v} \alpha}\right)^{-1} \text {. }
$$

The mass transfer coefficient describes the transport of gas from the gas phase across the air-water interface to the surface of the dropiets, and vice versa. Variable $a$ is the droplet radius $(\mathrm{cm}), D_{g}$ is the gas phase diffusion constant $\left(0.1 \mathrm{~cm}^{2} \mathrm{~s}^{-1}\right)$, and $v$ is the mean molecular speed. Gas-phase diffusion effects depend on the surface of the droplets and the gas-phase diffusion constant. Transfer across the air-liquid interface depends on the droplet radius and on the accommodation coefficient $\alpha$, which represents the probability of capture of gas molecules by water molecules. This formulation for the mass transfer coefficient neglects aqueous phase diffusion effects, which is valid for all the species considered. The accommodation coefficient is poorly known, and according to Lelieveld and Crutzen (1991) it is assumed to be equal to 0.2 for a highly soluble gas like $\mathrm{H}_{2} \mathrm{O}_{2}$ and equal to 0.05 for a less soluble gas like $\mathrm{SO}_{2}$. Consequently, diffusion in gas phase is the dominant process limiting the transfer of gases into the aqueous phase.

At each time step, we solve for all drops two primary equations that express the rate of concentration changes between gas and aqueous phase, respectively:

$$
\begin{aligned}
\frac{d C_{g}}{d t} & =-C_{g} L(D) k_{t}+\frac{C_{a}(D) k_{t}}{H_{\mathrm{eff}}} \\
\frac{d C_{a}(D)}{d t} & =C_{g} L(D) k_{t}-\frac{C_{a}(D) k_{t}}{H_{\mathrm{eff}}} .
\end{aligned}
$$

The variables $C_{g}$ and $C_{a}(D)$ are the gaseous- and aqueous-phase concentrations, respectively, as a function of drop radius from 1 to $5 \mu \mathrm{m}$, both of which are expressed in molecules per cubic centimeter of air; $H_{\text {eff }}$ is the effective Henry's law constant $\left(\mathrm{M} \mathrm{atm}^{-1}\right)$, which takes into account the possible dissociation of the chemical species in the aqueous phase as a function of the $\mathrm{pH}$; and $L(D)$ is the liquid water content in each size category (dimensionless). At each time step, a balance is made between gas phase and aqueous phase, and the results depend on the chemical species in aqueous phase and in gas phase. An exponential method ten times faster than the Gear method (1971) described by Chang et al. (1987) has been used to solve the system of equations (15) and (16). This exponential chemical solver has been tested by varying the time step from 0.5 to $10 \mathrm{~s}$. We find that a time step of $1 \mathrm{~s}$ can be used for a less soluble gas, whereas a time step of $5 \mathrm{~s}$ is required for the more soluble gas. Recently, Gregoire et al. (1993) have used this exponential method in the framework of a chemical aqueous phase module dealing with more extensive chemistry of ozone. They found good agreement between their results and those obtained by Jacob (1986) and Chameides (1984).

A series of tests on the chemical module has been carried out to determine the efficiency of drops, as a function of their diameter, in reaching equilibrium between gas and aqueous phase at $25^{\circ} \mathrm{C}$ for both a highly soluble gas and a less soluble one. The results obtained have been compared to the theoretical results obtained by Iribarne and Cho (1989). In Figs. 5a,b, the evolution of the concentration in aqueous phase by absorption of gas is presented for three different diameters of drops: $D=20 \mu \mathrm{m}, 0.2 \mathrm{~mm}$, and $1 \mathrm{~mm}$. Characteristic times for the attainment of equilibrium between gas phase and aqueous phase obtained by Iribarne and Cho are summarized in Table 1 . We can consider that the characteristic time to reach solubility equilibrium can be neglected when it is less than the microphysical time step $\Delta t=10 \mathrm{~s}$.

A comparison between Table 1 and Figs. 5a,b for all chemical species and for all drop diameters considered shows that the results obtained by our chemical module are consistent with the theoretical results of Iribarne and Cho. It is clear that solubility equilibrium can be assumed for cloud droplets for all relevant gases when the characteristic time is less than the microphysical time step. As can be seen in Fig. 5a and in Table 1, for a highly soluble gas, the limitation by mass transfer is not negligible for raindrops $(\tau=400 \mathrm{~s}$ for raindrops of diameter $0.2 \mathrm{~mm}$ ). Differences between two size categories of raindrops are significant when one diameter is five times greater than the other because then the characteristic time is higher by a factor of 10 . As it has previously been mentioned, the limitation of gas-phase transfer is inversely proportional to the surface area of the drops. In the case of a less soluble gas, we can consider that all drops are in equilibrium with their gas phase concentration because for large raindrops the characteristic time is equal to $1 \mathrm{~s}$.

These results serve to confirm our chemical module. Variations in characteristic times for reaching equilibrium are significant in terms of drop diameter and the chemical species considered. The spectral approach allows us to take into account these significant variations. 
In the calculations described above, the spectral distribution of raindrops and cloud drops and microphysical events have not been considered. Perdue and Beck (1988), however, show that the simultaneous occurrence of drops with different pollution levels may result in a situation where each individual drop is in chemical equilibrium with the gas phase, but the bulk chemical composition of the drops is not. Consequently, we also treat the scavenging of gas by cloud droplets as a function of their different diameter.

In the case of bulk parameterizations, cloud water is considered in equilibrium with its environment, and its variation depends only on the variation of cloud water by condensation. Then $S_{\mathrm{dis}}$ is written as follows:

$$
S_{\mathrm{dis}}=C_{g} H_{\mathrm{eff}} R T\left(\frac{\partial q_{\mathrm{cw}}}{\partial t}\right)_{\text {cond }} .
$$

The assumption for scavenging gas into cloud drops appears to be insufficient because, on the one hand, many authors have shown the nonlinearity in scavenging of gas and, on the other hand, Pandis and Seinfeld (1991) demonstrated that drops represented by an explicit model always have a greater capacity for uptaking $\mathrm{SO}_{2}$ from the gas phase than drops represented by a bulk approach. With this bulk parameterization, we can then expect an underestimate of the uptake of gas by cloud drops.

In rainwater, the limitation due to mass transfer is considered but usually parameterized. Drops are considered as falling through the air with a constant concentration in gas phase, $C_{a}$. The density flux $F$ of gas toward the drop is given by $F=k_{g}\left(C_{g}-C_{\mathrm{eq}}\right)$, where $C_{g}$ is the gas-phase concentration and $C_{\mathrm{eq}}$ is the value in equilibrium with the aqueous concentration. The coefficient $k_{g}=f D_{g} / r$ (where $D_{g}$ is the diffusivity in the gas phase and $r$ the drop radius) contains a correction factor that represents the mass transfer enhancement produced by the relative motion of the drop and the air and by drag-induced internal circulations.
TABLE 1. Relaxation time for acquiring solubility equilibrium.

\begin{tabular}{cccc}
\hline & $\tau(\mathrm{s})$ & $\tau(\mathrm{s})$ & $\tau(\mathrm{s})$ \\
$H_{\mathrm{eff}}\left(\mathrm{M} \mathrm{atm}^{-1}\right)$ & $D=20 \mu \mathrm{m}$ & $D=0.2 \mathrm{~mm}$ & $D=1 \mathrm{~mm}$ \\
\hline $10^{5}$ & 4 & 400 & 4000 \\
$10^{2}$ & $10^{-3}$ & $10^{-1}$ & 1 \\
\hline
\end{tabular}

As in Walcek et al. (1984), $f=1$ if $r<500 \mu \mathrm{m}, f$ $=2.5$ if $500<r<900 \mu \mathrm{m}$, and $f=20$ if $r>900 \mu \mathrm{m}$. The variation of concentration in rainwater, $S_{\mathrm{sca}}$, is then written as

$$
S_{\mathrm{sca}}=C_{g} H_{\mathrm{eff}} R T\left(\frac{\partial q_{\mathrm{rw}}}{\partial t}\right)\left[1-\exp \left(\frac{-6 k g}{D g H_{\mathrm{eff}} R T} d t\right)\right]
$$

As in the case for cloud water, the rate of change of the concentration in aqueous phase is linearly dependent on the variation of rainwater. The coefficient that represents the limitation by mass transfer is inversely proportional to the drop radius, whereas the limitation by mass transfer is governed by gas-phase diffusion inversely proportional to the surface area of the drops. This formulation overestimates this coefficient and then underestimates the efficiency of drops to uptake gas. Another point can be made regarding the correction factor, which considers only three size categories of raindrop diameter. As we have seen in section 2, raindrops are represented by a distribution of diameter between 0.1 and $1.0 \mathrm{~mm}$, for example, in the BR scheme, and only a single value of the correction factor is taken for all drops because scavenging is based only on the mean diameter of the distribution. Consequently, small drops are not taken into account, and this formulation can lead to an underestimate of the scavenging process.

The SP approach provides a more realistic description of processes involved in the scavenging of gas by
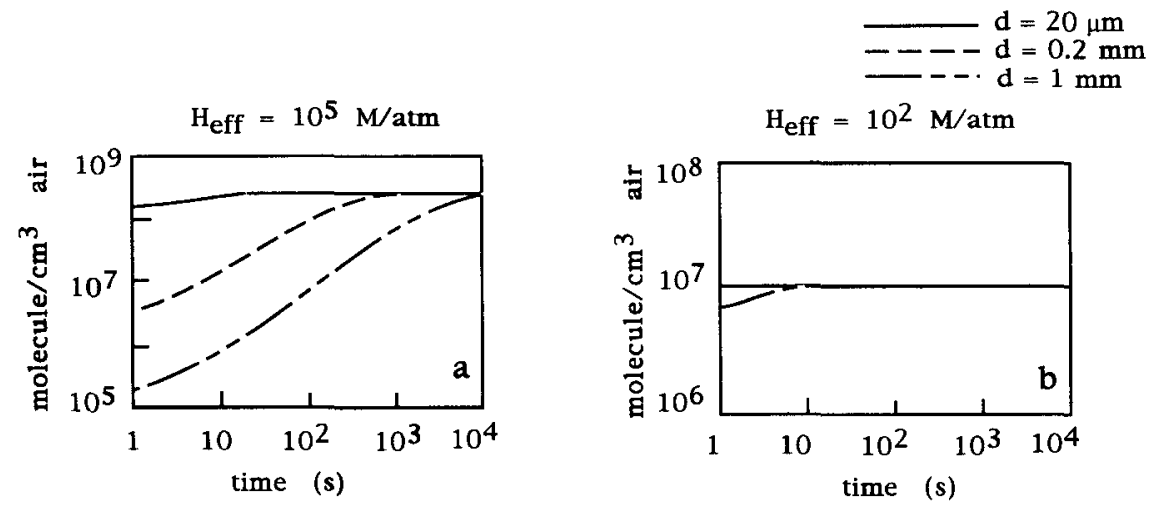

FIG. 5. Temporal evolution of chemical aqueous phase concentration in droplets of three diameters $(D=20 \mu \mathrm{m}, 0.2 \mathrm{~mm}$, and $1 \mathrm{~mm})$ for (a) a highly soluble gas $\left(H_{\mathrm{eff}}=10^{5} \mathrm{M} \mathrm{atm} \mathrm{at}^{-1}\right)$ and (b) a less soluble gas $\left(H_{\mathrm{eff}}=10^{2} \mathrm{M} \mathrm{atm}^{-1}\right)$. 
both cloud and raindrops in terms of diameter dependency, nonlinearity with respect to microphysical processes, and the balance between the gas phase and the aqueous phase. All these differences between bulk and detailed parameterizations will become even more pronounced in the dynamical framework because the spectral distributions and the microphysical history of raindrops are very different for the three schemes.

\section{Results and discussion}

In this section, we show the results from a complete simulation with the mountain wave scenario, including the chemical module previously described. The initial gas concentration is set equal to the constant value of 1 parts per billion ( $\mathrm{ppb}$ ) over the entire domain. In Fig. 6, results are presented for a highly soluble gas, where $H_{\mathrm{eff}}=10^{5} \mathrm{M} \mathrm{atm}^{-1}$. For the three microphysical parameterizations, vertical cross sections of chemical species concentration are shown in the gas phase (Fig. 6a) and in the aqueous phase for both cloud (Fig. 6b) and rain (Fig. 6c).

Maxima of gaseous-phase concentration in Fig. 6a are of the same order of magnitude (around $60 \mathrm{nmol}$ per cubic centimeter of air) for the three parameterizations. We can see that the occurrence of the cloud leads to a depletion of the gas phase concentration but that the spatial distribution and the intensity of this depletion are very different for the three parameterizations. With the K and BR schemes, the gas concentration decreases to $40 \mathrm{nmol} \mathrm{cm}{ }^{-3}$ within the cloud, and this decrease corresponds exactly with the spatial limit of the cloud presented before in Fig. 2a. With the SP scheme, in contrast, the minimum value of the concentration in gas phase is much lower $\left(10 \mathrm{nmol} \mathrm{cm}^{-3}\right)$, and the spatial extent of the depletion stretches downwind. As we have seen in the previous section, the SP scheme results in the uptake of more gas because, as Pandis and Seinfeld (1991) mentioned, when the spectral distribution of cloud drops or raindrops is consid-
KESSLER
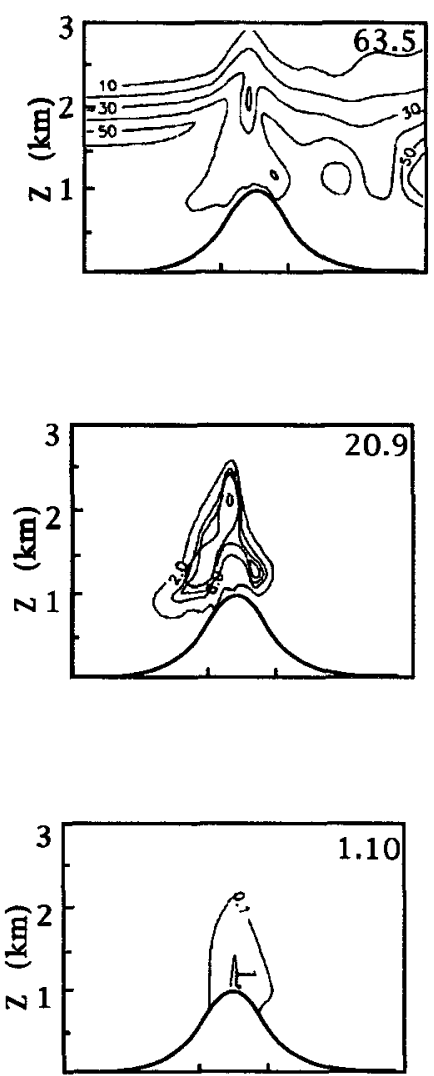

BERRY-REINHARDT

AIR

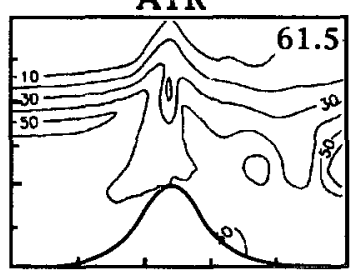

CLOUD

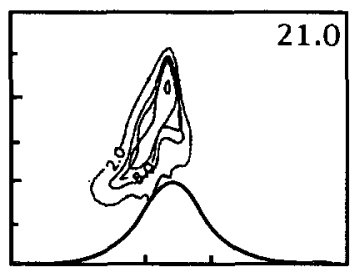

RAIN

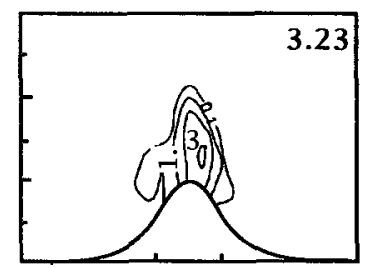

SPECTRAL
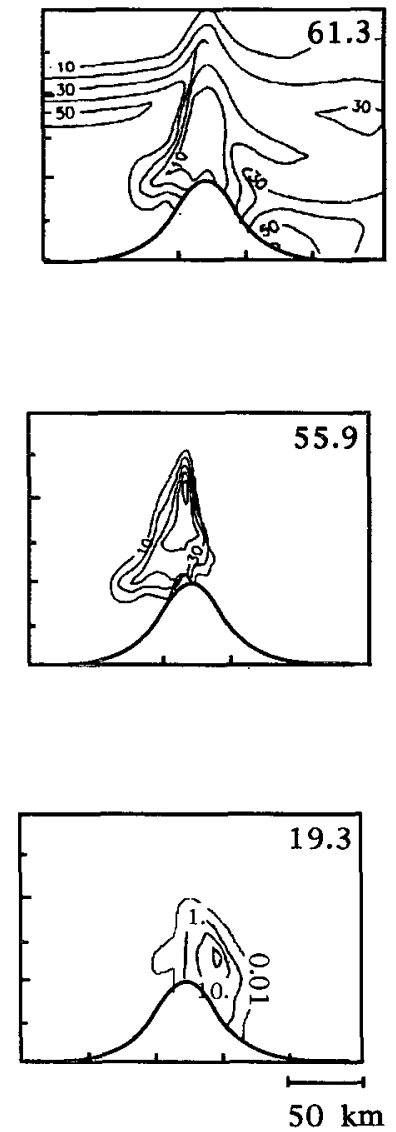

FIG. 6. Vertical cross section of chemical concentrations in (a) air, (b) cloud, and (c) rain environments for a highly soluble gas in nanomoles per liter of air, for the K, BR, and SP parameterizations. Maximum values are given in the upper-right corner of each figure. 
ered instead of a bulk mixing ratio, more gas is scavenged. With the SP scheme, absorption of gas is not linearly dependent on the variation of cloud-water mixing ratio, and the balance between gas-phase and aqueous-phase chemistry at each time step is made in terms of the whole cloud-water and rainwater mixing ratios. The spatial extent of the depletion on the downwind side of the mountain can be attributed to the presence of small raindrops reaching equilibrium in this area and scavenging more gas than the larger drops present in the BR and $\mathrm{K}$ schemes. At low levels on the downwind side of the mountain, the concentration in gas phase increases in the BR and SP schemes. Total evaporation of small drops allows for the desorption of gas. Also, since the presence of smaller drops are favored in the BR and SP schemes after partial evaporation, those small drops are advected downwind from the mountaintop and evaporate farther downwind than in the $\mathrm{K}$ scheme. In the $\mathrm{K}$ scheme, this process does not occur because relatively few small drops are present, and partial evaporation on large drops is not taken into account. With the SP scheme, the increase of the concentration in gas phase is more significant than with the BR scheme. In Fig. 4 we have seen that the evaporation rate for the SP scheme is much greater than for the BR scheme. More small drops that completely evaporate are present in the SP scheme, and in addition, partial evaporation of large drops significantly increases the aqueous concentration.

The aqueous concentrations in cloud water (Fig. 6b) are comparable for the BR and $\mathrm{K}$ schemes and reflect the spatial extent of the cloud. With the SP scheme, however, the intensity of the cloud concentration is twice as large and explains the greater depletion in the gas phase. The scavenging of gas by cloud drops is not linearly dependent on the evolution of the cloud-water content, and at each time step the balance between gas phase and aqueous phase is made. The underestimate of cloud concentration obtained by the $\mathrm{K}$ and $\mathrm{BR}$ schemes originates on the one hand from this linear dependency that does not take into account the advection of gas during two time steps, and on the other hand from the bulk representation of cloud water that limits gas scavenging.

This underestimate can be seen too in rainwater concentration fields (Fig. 6c), where the chemical species is transferred from cloud water to rainwater by coalescence. In the SP scheme, this effect of high concentration in rainwater is emphasized. With this scheme, more small drops are present in the rainwater, and partial evaporation on the downwind side of the mountain concentrates chemical species in raindrops. In the formulation of BR, we consider the mean diameter of raindrops and an average value for the correction ventilation factor $f$ to scavenge gas, and these approximations increase the effects of mass transfer limitations. We can also notice a greater absorption of gas by rainwater upwind from the mountaintop with the BR and SP schemes because rainwater is carried by smaller drops more efficient at uptaking gas than the greater raindrops in the K scheme. Also, in the SP scheme, smaller drops are more sensitive to wind drift effects and have a longer residence time in the downwind part of the domain, resulting in more time for absorbing gases.

The SP scheme allows us to obtain the distribution of the concentration (in moles per liter of water) as a function of raindrop diameter, which is plotted in Fig. 7 for three different points of the domain at three different altitudes. The results obtained for a highly soluble gas (solid line) and a less soluble gas (dashed line) are presented. On the downwind side of the mountain, rain formation occurs after having accreted cloud droplets, and we observe for the two gases an increase in aqueous phase concentration during the formation of rain.

On the upwind side of the mountain, corresponding to the area where autoconversion occurs, the two gases dissolve following a similar raindrop size dependency. All drops present in this area, from 0.1 to $0.5 \mathrm{~mm}$ in diameter, have almost the same concentration because, as we have previously seen, small drops reach chemical equilibrium quickly. Differences between the two gases appear when large drops are formed on the top of the mountain. For a highly soluble gas, the aqueous concentration in raindrops decreases when their diameter increases. Chemical concentrations increase in all drops, but mass transfer limitations prevent large drops from reaching equilibrium. The differences are smaller for a less soluble gas since the time to reach equilibrium is smaller, and microphysical processes act to homogenize the concentration for all diameters of raindrops (Flossmann et al. 1987). On the downwind side of the mountain, large drops are created by the self-collection process. For the two chemical species, whatever their solubility is, the aqueous concentration decreases when the drop diameter increases. This characteristic is emphasized for highly soluble gas, where, for example, at $360 \mathrm{~m}$ in altitude the concentration for a drop with a diameter of $0.1 \mathrm{~mm}$ is equal to $2 \times 10^{-4} \mathrm{~mol} \mathrm{~L}^{-1}$ of water and is equal to $2 \times 10^{-5} \mathrm{~mol} \mathrm{~L}^{-1}$ of water for a diameter of $2 \mathrm{~mm}$. Mass transfer limitations are responsible for the decrease of the aqueous concentration as a function of the raindrop diameter, but another process acts because this behavior also occurs with a less soluble gas. In this part of the domain, evaporation processes play an important role. The detailed treatment of partial evaporation increases the aqueous concentration in drops and acts to concentrate chemical species inside drops. Drops are then unable to release gas. This behavior is consistent with the increase in gas concentrations in Fig. 6a. Because the SP scheme considers the details of the evolution for the chemical concentration as a function of the raindrop diameter, partial evaporation is more important in the SP scheme than in the BR scheme. Individual small drops quickly 
reach chemical equilibrium and release more gas than the well-mixed solution with the same raindrop diameter obtained from the BR scheme. This explains the greater desorption area in gas phase on the downwind side of the mountain observed with the SP scheme than with the BR scheme. When considering gas scavenging, it is important to consider the distribution of raindrop diameter because significant differences appear when the partial evaporation process concentrates the chemical species inside the drops and subsequently releases gas.

In Table 2, maximum values of the deposition rates corresponding to precipitation rates maxima are presented for the three parameterizations for the case of a highly soluble gas and also for a less soluble gas. For the two species considered, those deposition rates maxima are much greater with the SP scheme. Also, with the SP scheme the average chemical concentration in rainwater is greater because the assumptions regarding the distribution of the aqueous concentration as a function of raindrop diameter are favoring gas scavenging. Partial evaporation concentrates aqueous concentrations, and drops are unable to release gas. With the SP scheme, raindrops are centered on a larger diameter than with the BR scheme and are more efficient to sediment. The proportionality factor between highly soluble gas and a less soluble one is not identical. With the $\mathrm{K}$ scheme, the influence of the limitation by
TABLE 2. Maximum values of deposition rates $\left(\mathrm{mg} \mathrm{m}^{-2} \mathrm{~s}^{-1}\right)$.

\begin{tabular}{lccc}
\hline & Kessler & Berry-Reinhardt & Spectral \\
\hline $\begin{array}{l}\text { Highly soluble } \\
H=10^{5} \mathrm{M} \text { atm }\end{array}$ & & & \\
$\begin{array}{l}\text { Less soluble } \\
H=10^{2} \mathrm{M} \mathrm{atm}^{-1}\end{array}$ & 0.51 & 0.59 & 3.61 \\
\hline
\end{tabular}

mass transfer is significant with respect to evaporation. For the BR and SP schemes, partial evaporation concentrates gas inside the drops. Also, for low soluble species the limitation by mass transfer for acquiring equilibrium is not as important as for the soluble case.

\section{Conclusions}

A comparative study of three microphysical schemes in a mesoscale model was made to examine the impact of each scheme on gas scavenging and wet deposition. Rainfall rates are comparable in intensity, but their downwind spreading is markedly larger in both the BR and SP cases than in the $\mathrm{K}$ case. The $\mathrm{K}$ parameterization produces raindrop size spectra centered on larger diameters than obtained from the BR and SP schemes. More small drops are present in those two schemes, and those smaller drops are more susceptible to the advection process. The $\mathrm{K}$ scheme considers only the

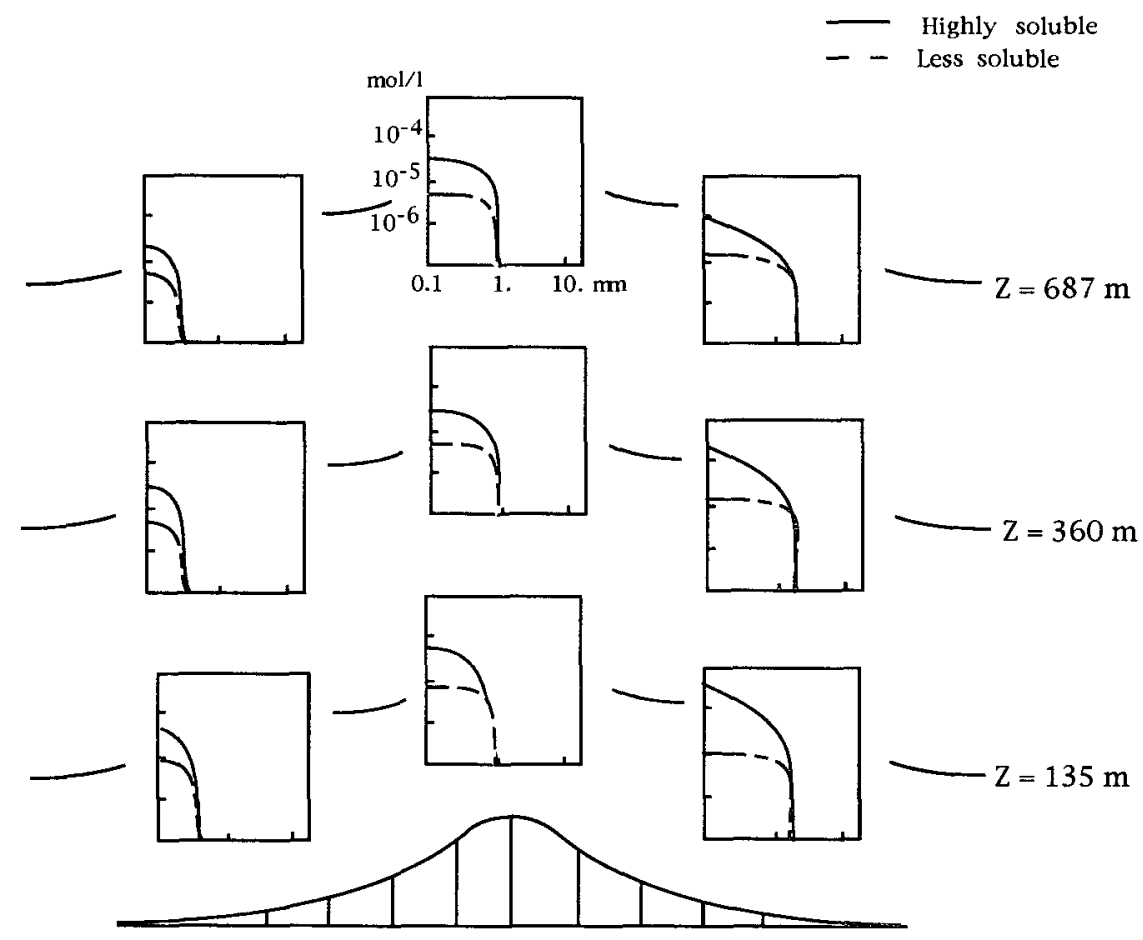

FIG. 7. Aqueous concentrations in moles per liter of water for a highly soluble gas (solid lines) and a less soluble gas (dashed lines) as a function of raindrops diameter obtained with the SP scheme for three grid points located at the top, on the upwind side, and on the downwind side of the mountain, respectively, for three vertical levels of the model. 
complete evaporation process, whereas the SP and BR schemes treat in detail the partial and complete evaporation process, resulting in more drops on the downwind side of the mountain. When considering microphysical processes appropriate for the inclusion in a meteorological model, the BR scheme appears to be a middle approach because it is not too expensive with respect to calculation time, and the results obtained are comparable to those obtained with a spectral microphysical model.

The coupling of the scavenging process with a bulk microphysical approach appears insufficient because intricate chemical processes are not linearly dependent on the evolution of water content, as the SP scheme shows. Contrary to bulk parameterizations, a spectral scheme does not consider rainwater as a well-mixed solution, and this assumption leads to a larger efficiency of rainwater to scavenge gas. The SP scheme provides additional information on raindrop chemical concentration spectra, which is important when considering evaporation processes. Partial evaporation concentrates gas in the liquid phase and allows chemical equilibrium to be reached more quickly for large drops with the subsequent release of gas. This behavior also shows up in the BR scheme. Evaporation and sedimentation processes reduce the differences between highly soluble gas and less soluble gas, and deposition rates are in the same order of magnitude as the SP scheme. The same behavior is observed in the spatial and temporal evolutions of gases in the BR and SP schemes, but the efficiency of releasing gases through evaporation is lower in the BR scheme than in the SP one. This phenomenon is not even observed in the $\mathrm{K}$ scheme. For the study of gas scavenging and chemical reactions in aqueous phase, it is necessary to have a microphysical approach that considers diameter of drops and also to have a chemical module completely coupled with microphysical and dynamical processes because wet deposition is not linearly dependent on cloud processes. It should also be pointed out that in this study, as a first step, we have neglected chemical reactions, and that the amount of dissolution could be different when chemical reactions are allowed to take place in the aqueous phase. The results of this study, however, still stand qualitatively, and we can conclude that the parameterization of Berry and Reinhardt appears to be a good compromise for studying chemical processes, but absorption should be reviewed in terms of the linear dependency between scavenging of gas and the evolution of water mixing ratio.

Acknowledgments. The authors wish to thank R. Pejoux and $\mathrm{F}$. Besserve for computing assistance.

\section{REFERENCES}

Ayers, G. P., and T. V. Larson, 1990: Numerical study of droplet size dependent chemistry in oceanic, wintertime stratus cloud at southern mid-latitudes. J. Atmos. Chem., 11, 143-167.
Beard, K. V., and H. R. Pruppacher, 1971: A wind tunnel investigation of the rate of evaporation of small water drops falling at terminal velocity in air. $J$. Atmos. Sci., 28, 1455-1464.

, and H. T. Ochs III, 1993: Warm-rain initiation: An overview of microphysical mechanisms. J. Appl. Meteor., 32, 608-625.

Berry, E. X., and M. P. Pranger, 1974: Equations for calculating the terminal velocities of water drops. J. Appl. Meteor., 13, 108113.

, and R. L. Reinhardt, 1974a: An analysis of cloud drops growth by collection. Part II: Single initial distributions. J. Atmos. Sci., 31, 1825-1831.

_- and 1974b: An analysis of cloud drops growth by collection. Part III: Accretion and self-collection. J. Atmos. Sci., 31, 2118-2126.

Carmichael, G. R., and L. K. Peters, 1984: An Eulerian transporttransformation-removal model for $\mathrm{SO}_{2}$ and sulfate. I. Model development. Atmos. Environ., 18, 937-951.

Chameides, W. L., 1984: The photochemistry of a remote marine stratiform cloud. J. Geophys. Res., 89, 4739-4755.

Chang, J. S., R. A. Brost, I. S. Isaksen, S. Madronich, P. Middleton, W. R. Stockwell, and C. J. Walcek, 1987: A three-dimensional Eulerian acid deposition model: Physical concepts and formulation. J. Geophys. Res., 92, 14 681-14 700.

Chaumerliac, N., E. Richard, R. Rosset, and E. C. Nickerson, 1990: Impact of two microphysical schemes upon gas scavenging and deposition in a mesoscale meteorological model. J. Appl. Meteor., 30, 88-97.

Ferretti, R., G. Visconti, and F. Giorgi, 1993: Chemistry and transport of sulfur compounds from large oil fires studied with 2D mesoscale model. Ann. Geophys., 11, 68-77.

Flossmann, A. I., H. R. Pruppacher, and J. R. Topalian, 1987: A theoretical study of the wet removal of atmospheric pollutants. Part II: The uptake and redistribution of $\left(\mathrm{NH}_{4}\right)_{2} \mathrm{SO}_{4}$ particles and $\mathrm{SO}_{2}$ gas simultaneously scavenged by growing cloud drops. J. Atmos. Sci., 44, 2912-2923.

Gear, C. W., 1971: The automatic integration of ordinary differential equations. $A C M$ Comm., 14, 176-190.

Gregoire, P. J., N. Chaumerliac, and E. C. Nickerson, 1993: Impact of cloud dynamics on tropospheric chemistry: Advances in modeling the interactions between microphysical and chemical processes. J. Atmos. Chem., in press.

Gunn, R., and G. D. Kinzer, 1949: The terminal velocity of fall for water droplets in stagnant air. J. Meteor., 6, 243-248.

Hales, J. M., 1989: A generalized multidimensional model for precipitation scavenging and atmospheric chemistry. Atmos. Environ., 23, 2017-2031.

Hegg, D. A., and T. V. Larson, 1990: The effects of microphysical parameterization on model predictions of sulfate production in clouds. Tellus, 42B, 272-284.

Iribarne, J. V., and H. R. Cho, 1989: Models of cloud chemistry. Tellus, $41 \mathrm{~B}, 2-23$.

Jacob, D. J., 1986: Chemistry of $\mathrm{OH}$ in remote clouds and its role in the production of formic acid and peroxymenosulfate. $J$. Geophys. Res., 91, 9807-9826.

Kessler, E., 1969: On the Distribution and Continuity of Water Substance in Atmospheric Circulations. Meteor. Monogr., No. 32, Amer. Meteor. Soc., 84 pp.

Le Cam, M. N., and H. Isaka, 1989: Retrieval of microphysical variables by diagnostic modeling study: Comparison between parameterized and detailed warm microphysics. Tellus, 41A, $338-$ 356.

Lee, L. Y., 1986: Numerical simulation of chemical and physical properties of cumulus clouds. Atmos. Environ., 20, 767-771.

Lelieveld, J., and P. J. Crutzen, 1991: The role of clouds in tropospheric photochemistry. J. Atmos. Chem., 12, 229-267.

Marshall, J. S., and W. McK. Palmer, 1948: The distribution of raindrops with size. J. Meteor., 5, 165-166.

Nickerson, E. C., E. Richard, R. Rosset, and D. R. Smith, 1986: The numerical simulation of clouds, rain, and airflow over the Vosges and Black Forest Mountain: A meso- $\beta$ model with parameterized microphysics. Mon. Wea. Rev., 23, 477-487. 
Noone, K. J., R. J. Charlson, D. S. Covert, J. A. Ogren, and J. Heintzenberg, 1988: Cloud droplets: Solute concentration is size dependent. J. Geophys. Res., 93, 9477-9482.

Ogren, J. A., and R. J. Charlson, 1992: Implications for models and measurements of chemical inhomogeneities among cloud droplets. Tellus, 44B, 208-225.

Pandis, S. N., and J. H. Seinfeld, 1991: Should bulk cloud water or fogwater samples obey Henry's law? J. Geophys. Res., 96, $10791-10798$.

Perdue, E. M., and K. C. Beck, 1988: Chemical consequences of mixing aerosol droplets of varied pH. J. Geophys. Res., 93, 691698.

Pruppacher, H. R., and J. D. Klett, 1978: Microphysics of Clouds and Precipitation. D. Reidel, $714 \mathrm{pp}$.

Richard, E., and N. Chaumerliac, 1989: Effects of different param- eterizations on the simulation of mesoscale orographic precipitation. J. Appl. Meteor., 28, 1197-1212.

Roelofs, G. J. H., 1992: On the drop and aerosol size dependence of aqueous sulfate formation in a continental cumulus cloud. Atmos. Environ., 26A, 2309-2321.

Schwartz, S. E., 1986: Mass-transport considerations pertinent to aqueous phase reactions of gases in liquid water clouds. Chemistry of Multi-phase Atmospheric Systems, W. Jaeschke, Ed., Springer, 415-471.

Walcek, P. K., H. R. Pruppacher, J. H. Topalian, and S. K. Mitra, 1984: On the scavenging of $\mathrm{SO}_{2}$ by cloud and raindrops: II. An experimental study of $\mathrm{SO}_{2}$ absorption and desorption for water drops in air. J. Atmos. Chem., 1, 291-306.

Waldvogel, A., 1974: The $N_{0}$ jump of raindrop spectra. J. Atmos. Sci., 31, 1067-1078. 